\title{
NUEVA SEDE DEL BANCO HIPOTECARIO DE ESPAÑA. MADRID. ESPAÑA
}

\author{
(NEW OFFICE BUILDING FOR THE BANCO HIPOTECARIO DE ESPAÑA)
}

José Ignacio González Pérez, Arquitecto

Director de Proyectos de SGV

Fecha de recepción: $15 \cdot \mathrm{XI}-88$

\section{RESUMEN}

El nuevo edificio de oficinas para el Banco Hipotecario de España, situado en el centro de Madrid en el paseo de Recoletos, $n .^{\circ} 12$, constituye un ejemplo característico en la ciudad de un determinado proceso constructivo. La obligada consideración del paisaje urbano ha tenido como consecuencia la conservación y restauración de las fachadas del edificio primitivo. En el proceso se han utilizado andamios estabilizadores y gunitado interior de dichas fachadas.

La necesidad de vaciar el solar para construir tres sótanos, asi como la presencia de las medianerías colindantes, han conllevado la construcción de muros pantallas y pilotes perimetrales con antifuniculares de arriostramiento.

El nuevo edificio responde a las necesidades de un banco moderno, asi pues va dotado de un sistema automatizado de gestión y control.

\section{SUMMARY}

The new office building of the Banco Hipotecario de España (Mortgage Bank of Spain) located in downtown Madrid at 12 Paseo de Recoletos, is one of the most characteristic examples of a determinate construction procedure in this city. The original façades of the building were preserved and restored due to the necessity of taking into account the urban landscape. Stabilizing scaffolding and gunite in the interior of said façades were used in the restoration process.

Because of the necessity of clearing and removing earth from the lot to construct three basements, as well as the presence of joint party walls, core walls and perimetre piles with antifuniculars for shoring up were also constructed.

This new building meets all the needs of a modern bank, being equipped with an automated management and control system.

\section{Antecedentes históricos del entorno}

En el año 1846 el banquero Marqués de Salamanca encarga al arquitecto Narcisco Pascual y Colomer el proyecto de una residencia-palacio en el Paseo de Recoletos.

La parcela sobre la cual se proyecta y construye el citado palacio perteneció en el siglo XVII a la huerta del convento de los monjes Recoletos.

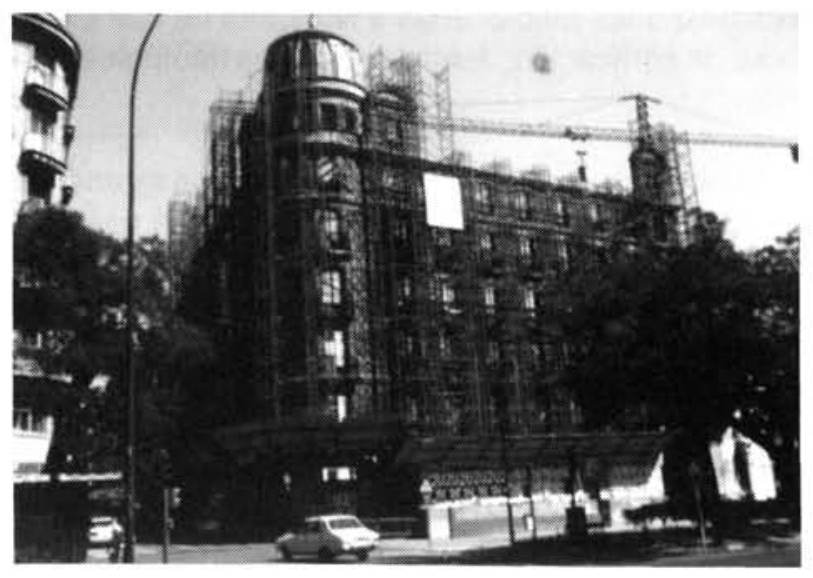

(c) Consejo Superior de Investigaciones Científicas Licencia Creative Commons 3.0 España (by-nc)
La edificación, de planta cuadrada, se sitúa en el centro de esta gran parcela rodeándolo de jardinería.

En el parcelario de Madrid, realizado y publicado por el Instituto Geográfico y Estadístico en 1874, puede apreciarse claramente la ordenación de la manzana comprendida entre las calles Alcalá, Serrano, Recoletos y Paseo de Recoletos. Dicha manzana aunque condicionada por los edificios palaciegos, empieza a configurarse en su frente de la calle Recoletos, como una ordenación típica de manzana cerrada.

Más adelante toda este área quedará englobada en el llamado ensanche Almagro-Castellana.

Puesto en marcha el proceso constructivo siguiendo las pautas urbanisticas del ensanche AlmagroCastellana se levantan bloques de viviendas que, alineados, colman los perimetros de las manzanas y configuran las calles.

Asi ocurre en la calle Recoletos y, concretamente, asi se origina el edificio objeto del presente trabajo situado en la esquina formada por la calle Recoletos y el Paseo de Recoletos. 


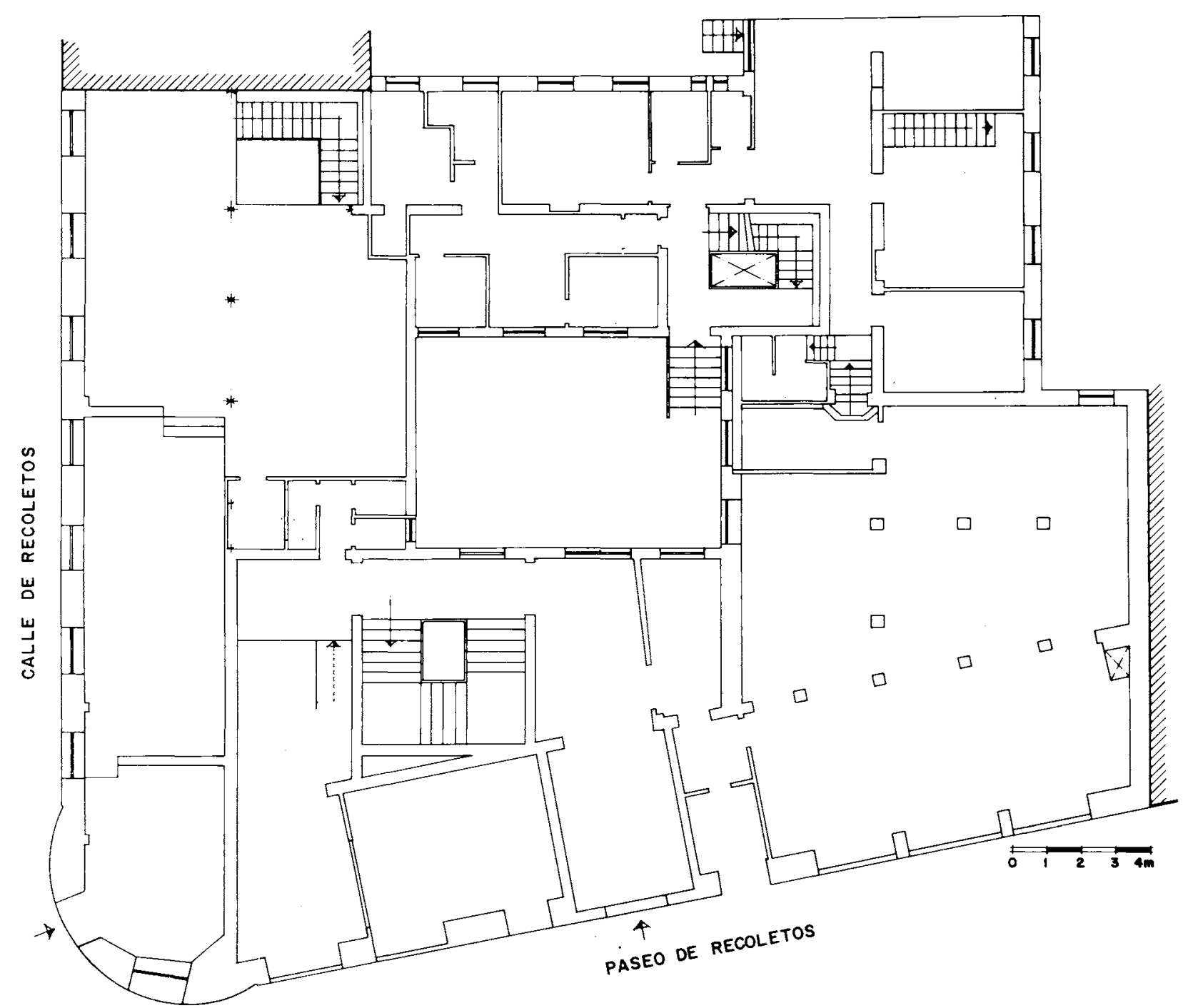

Planta baja del antiguo edificio.

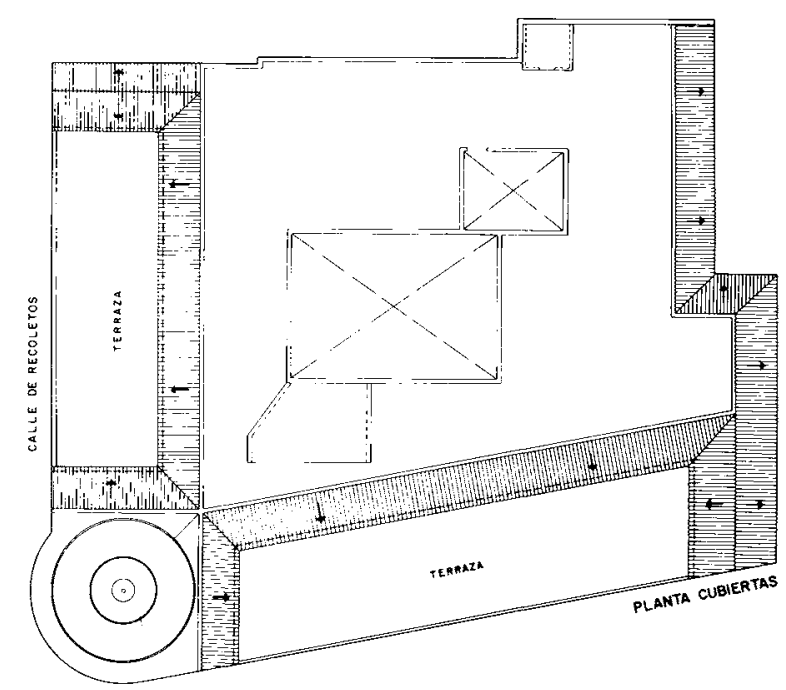

Planta de cubiertas del antiguo edificio.
El resultado de este proceso es una mezcla de edificios diseñados para ir conformando una manzana cerrada y palacios que, permaneciendo como edificaciones exentas en el interior de dichas manzanas, se resisten a su demolición. Naturalmente en esta descripción sólo queremos destacar un hecho, sin entrar en jucios de valor, sobre la bondad o no de mantener dichas edificaciones.

Los edificios de viviendas muestran provisionalmente sus desnudas medianerias a la espera de que el proceso de edificación, dentro de su línea tipológica, continúe.

Esta heterogeneidad edificatoria es la que se encuentra Joaquin Saldeña cuando se le encargan una serie de trabajos en el Palacio del Marqués de Salamanca y diseña las celosías de madera y estructura metálica que visten las medianerías colindantes.

Una vez hecho el necesario recorrido por los antecedentes históricos del entorno, vamos a describir de un modo concreto los aspectos que han determinado las decisiones constructivas adoptadas. 


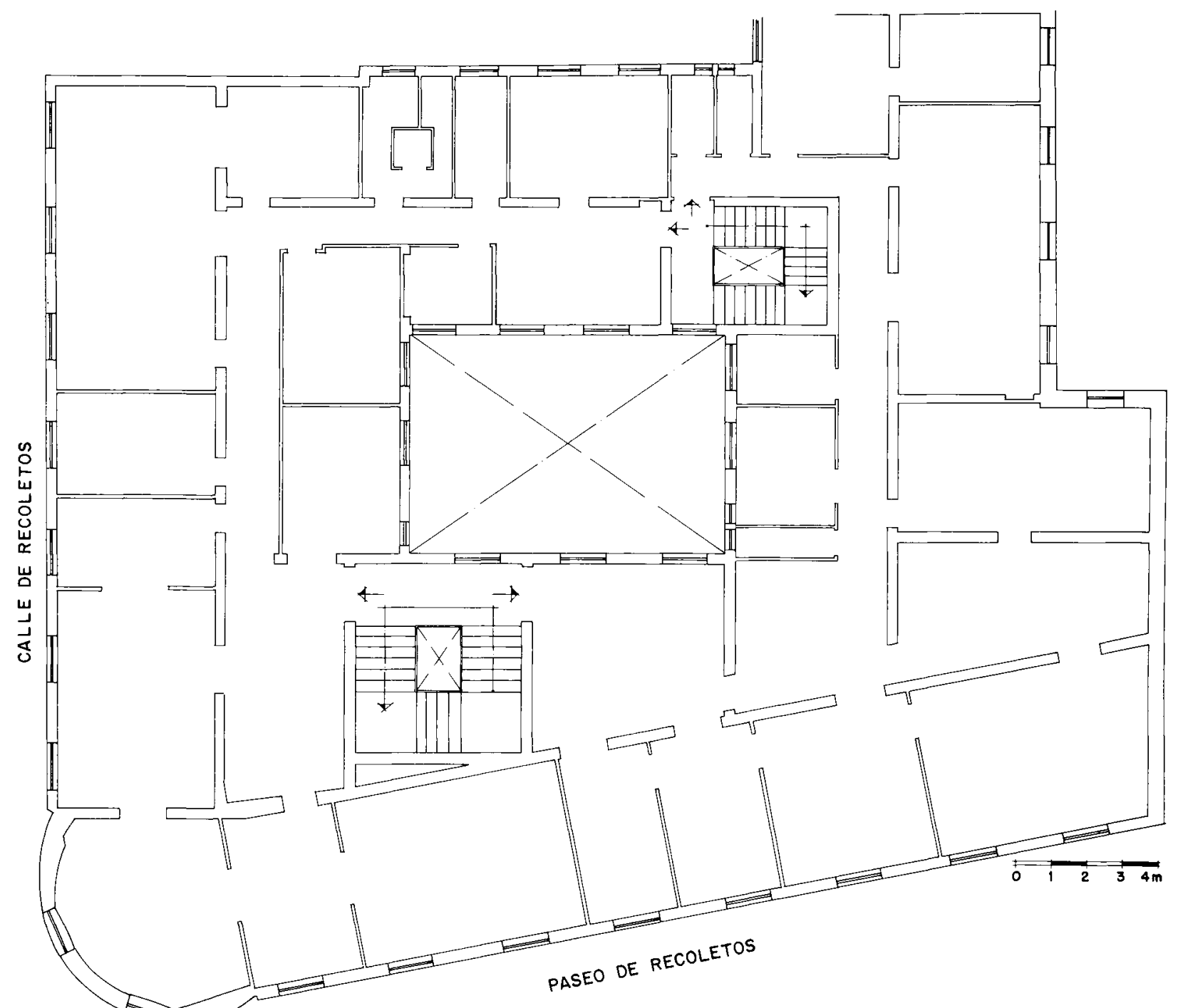

Planta primera del antiguo edificio.

Tal vez esa imagen de la celosía, sin menosprecio de la sensibilidad de su diseño, sea la razón que la ha hecho merecedora de toda consideración.

Disponiamos de un edificio originariamente de viviendas que habia de transformarse en un edificio de oficinas, pero manteniendo íntegro su aspecto exterior.

El edificio en cuestión poseía una estructura resistente de muros de carga que compartimentaba en exceso al espacio, y que se encontraba muy deteriorada y con una capacidad portante claramente insuficiente para el nuevo uso.

El programa del nuevo edifico exigia la construcción de tres sótanos para albergar instalaciones propias del Banco como cámaras acorazadas, archivos y aparcamiento.

La medianeria con el actual banco o fachada sur se encontraba "decorada" con la representación de un frontón coronando unos falsos huecos y, por fin, con la famosa celosía cuya presencia se ha convertido en una imagen urbana fácil de recordar para los madrileños.
Debido, pues, a la inadecuación de la estructura, el cambio de uso del lugar y la necesidad de construir tres sótanos la consecuencia directa fue la demolición y vaciado del viejo edificio manteniendo en pie las fachadas.

\section{Proceso de diseño}

Los principios en los que se ha basado el diseño han sido los siguientes:

1) Programa de necesidades del Banco Hipotecario de España con la idea presente de actualizar la imagen corporativa y crear una nueva cultura de empresa.

2) Consecución de un edificio de oficinas de alta tecnología en cuanto a su construcción y de flexibilidad de uso a lo largo del tiempo en cuanto a su funcionalidad. 


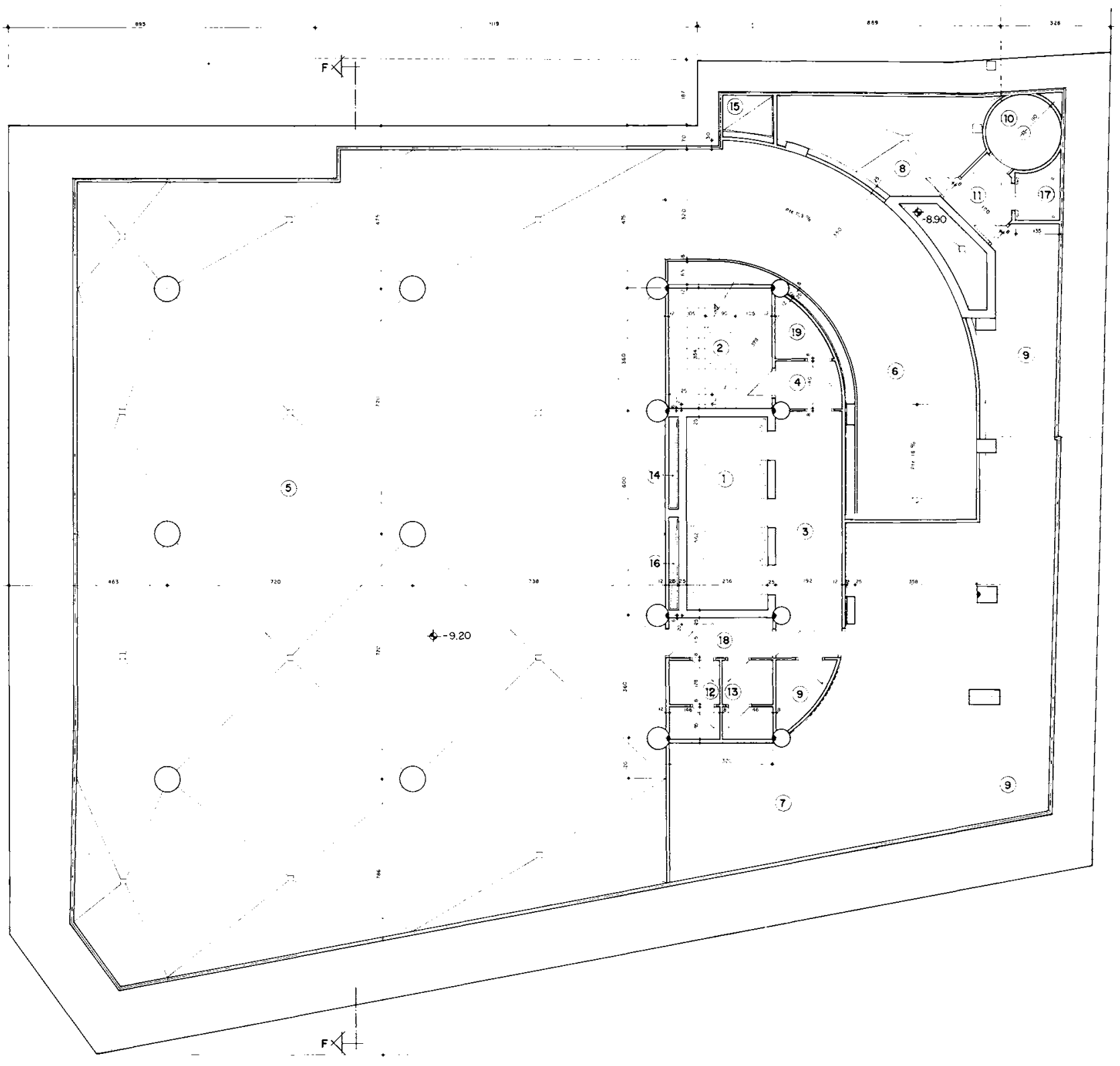

Planta sótano $3 .^{\circ}$

1.-Ascensores. 2.-Escalera acceso sótanos a baja. 3--Vestibulo ascensores. 4.-Vestibulo independencia. 5.-Aparcamiento. 6.-Rampa vehiculos. 7.-Almacén general o archivo. 8.-Grupos de presión para incendios. 9.-Almacén general o archivo. 10.-Escalera acceso a almacenes, archivo e instalaciones. 11.-Vestibulo independencia. 12.-Aseo de hombres. 13.-Aseo de mujeres. 14.-Conductos eléc. tricos. 15. - Ventilación natural aparcamiento. 16. - Ventilación forzada aparcamiento. 17.-Montacargas. 18. - Vestibulo aseos. 19.-Cuadros electricos de planta.

3) Consideración de la edificabilidad admisible según la normativa urbanística, asi como de los condicionamientos espaciales extraídos de la normativa de incendios.

4) Inquietudes estéticas personales y la toma de conciencia del significado urbanístico implícito en la obligatoriedad de mantenimiento de fachadas.

\section{Análisis de los citados principios}

Con respecto al uso del edificio, el Banco Hipotecario de España necesitaba un planta baja para patio de operaciones en unión con una planta primera de atención

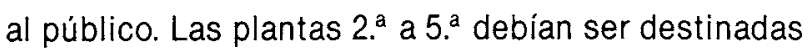
a oficinas generales, zonificando un área de oficina celular o compartimentada en despachos y un área mayor de oficina abierta.

La planta $6 .^{a}$, más pequeña que las anteriores debido a la existencia de sendas terrazas a lo largo de las fachadas, se determinó fuera destinada a la dirección general. Esto implicaria un tratamiento diferenciado y una estudiada compartimentación.

En el primer sótano se instalarian, además de otros servicios, aparcamiento y almacén. En los sótanos segundo y tercero, aparcamiento y archivo central. 
Otro aspecto que ha condicionado el diseño ha sido el esquema circulatorio interno según las necesidades del B. H. E. Se proyectaron tres accesos: uno al patio de operaciones, otro al edificio de oficinas propiamente dicho y un tercer acceso que conecta con el antiguo palacio. La interrelación entre los accesos descritos y la consideración del acceso de vehículos al garaje han influido determinantemente en la posición del núcleo de comunicaciones verticales y, por tanto, en la distribución general de la planta.

La intención de conseguir un edificio flexible en su uti. lidad nos ha llevado a la regularidad y modulación en los espacios de oficina abierta. Se elige como módulo los $0,60 \mathrm{~m}$, de manera que la luz entre pilares es de 7,20 , es decir, de 12 módulos. Esto nos ha permitido la coincidencia entre elementos constructivos de techo, placas de $0,30 \times 1,20$, luminarias $(4 \times 36)$ de $0,60 \times 1,20$ y losetas de moqueta en suelo de $0,60 \times 0,60$. Por otro lado con la distancia entre ejes de pilares de 7,20 hemos obtenido en garajes tres plazas amplias de 2,40 de ancho cada una.
Asimismo se ha modulado convenientemente el reparto de conductos y tomas en el suelo de teléfono, electricidad e informática.

La intención de construir un edificio "high tech" conlleva un sistema de instalaciones de climatización, de electricidad y de detección y protección de incendios sofisticados, todos ellos regidos y controlados por ordenador.

La consideración de la edificabilidad admisible nos ha obligado a compensar de algún modo la no edificabilidad del patio de parcela existente en el edificio original.

En nuestras intenciones estéticas personales, y considerando el impacto que precisaba el B. H. E. con su nueva sede, subyacia en nuestro interior el deseo de utilizar un lenguaje formal actual haciendo "dialogar" los elementos tecnológicos con los más tradicionales. El único modo de controlar el resultado ha sido llegando en el diseño hasta las últimas consecuencias.
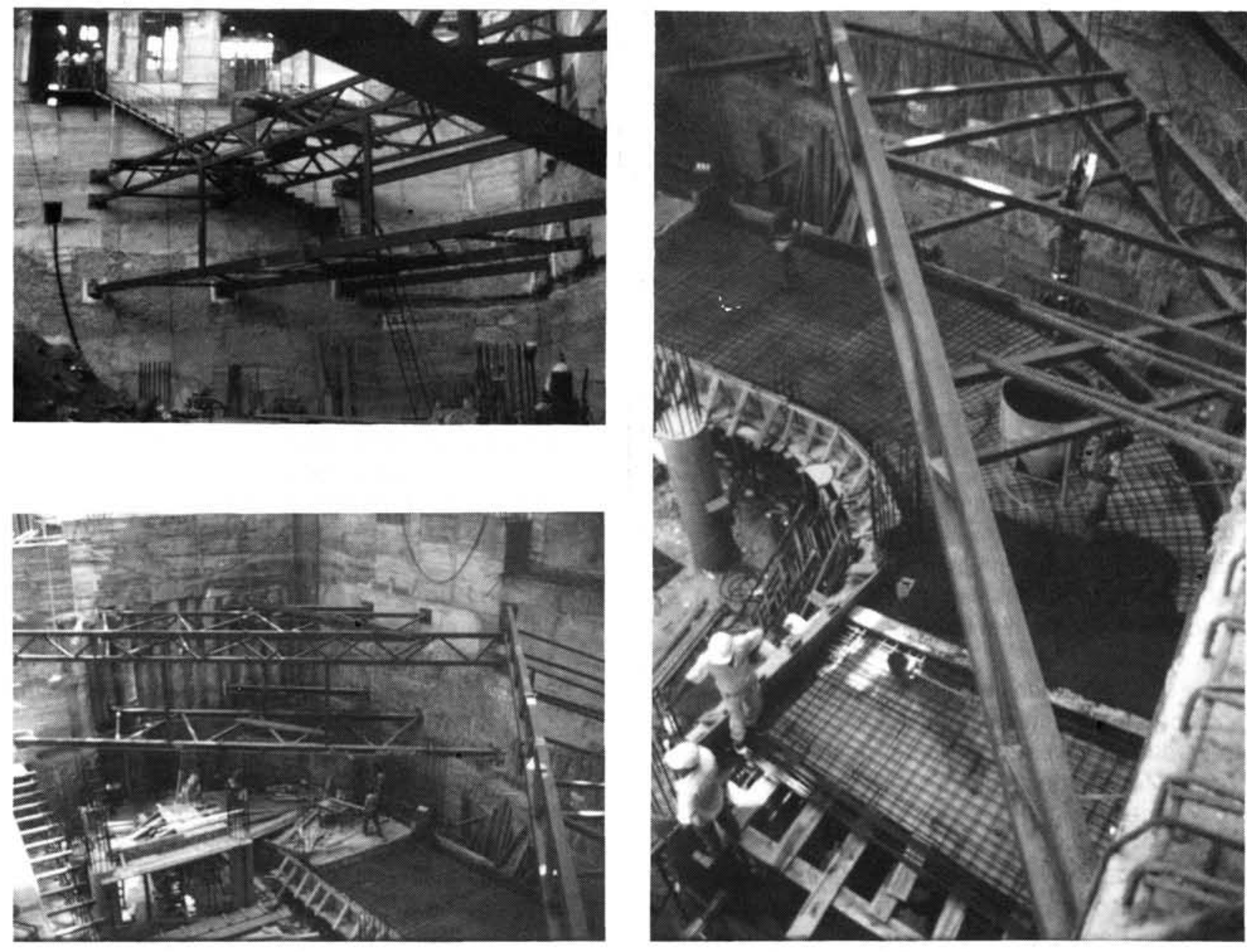


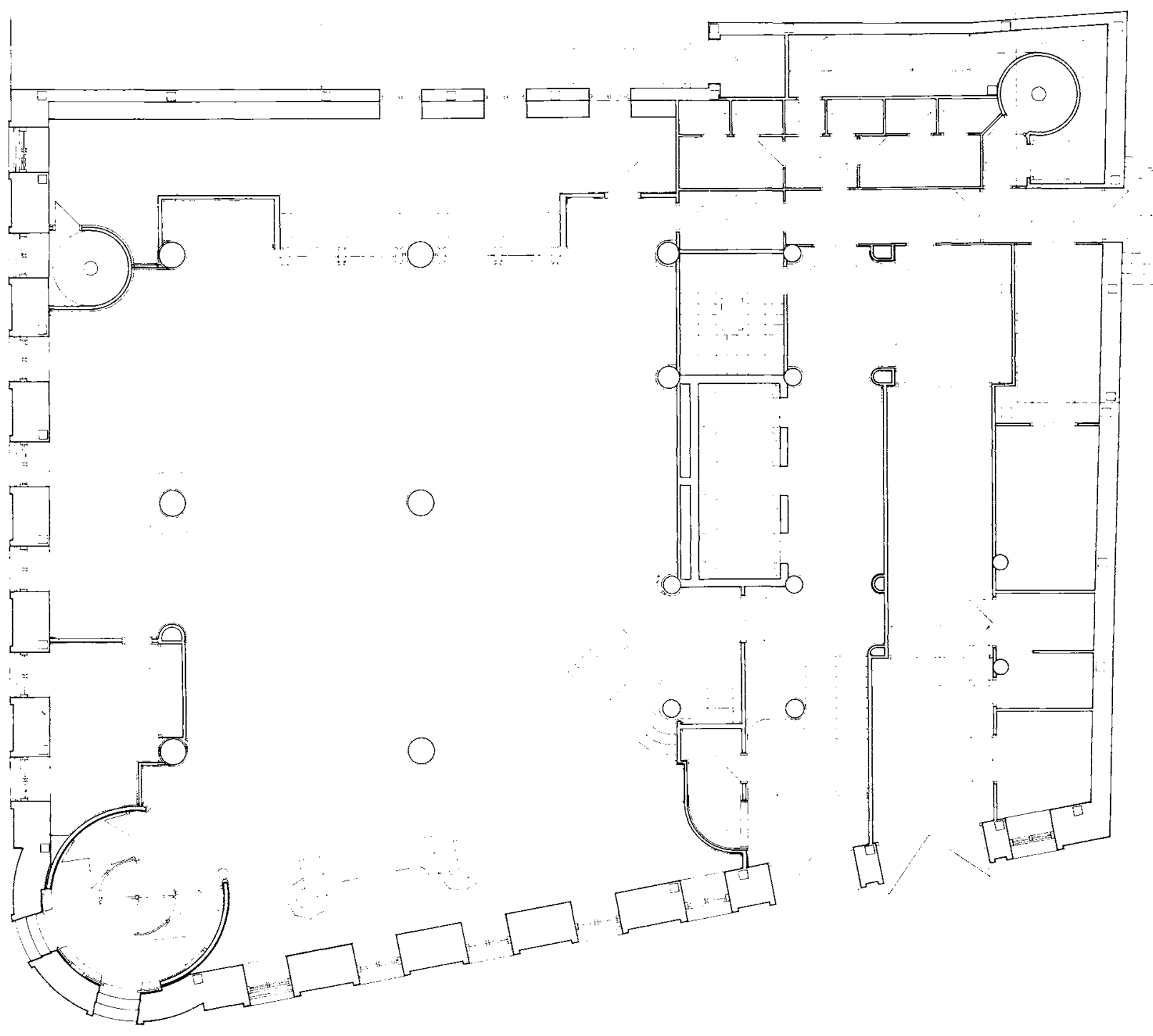

Planta baja del nuevo edificio.

\section{Conclusiones generales de diseño}

Amalgamados todos los puntos anteriormente descritos, pero jerarquizados según el criterio personal, llegamos al siguiente resultado de diseño:

- Se situó el núcleo de comunicaciones verticales en sentido perpendicular al Paseo de Recoletos dividiendo claramente las plantas de trabajo en dos zonas: Zona norte de oficina abierta y Zona sur de oficina celular.

- La no edificabilidad del antiguo patio de parcela se compensó con otro patio situado en fachada de $\mathrm{Pa}$ seo de Recoletos, a lo largo de la zona norte destinada a oficina abierta.
La situación de este patio nos permitió ortogonalizar dicha zona norte, absorbiendo con su forma de trapecio la irregularidad, consecuencia del ángulo inferior a $90^{\circ}$ formado por el Paseo de Recoletos y la calle Recoletos.

Por otro lado la situación elegida del patio ha evidenciado el carácter escenográfico de la vieja fa. chada, potenciando el espacio público de plantas baja y primera y consiguiendo un eficaz aislamien. to térmico y acústico.

- Se ha acentuado el carácter emblemático de la esquina del edificio mediante la significación de su forma cilindrica y un tratamiento diferenciado en todas las plantas. Dicho tratamiento se radicaliza en el acceso al patio de operaciones de la planta baja y en el diseño de la sala de juntas ubicada en el torreón de coronación de dicha esquina. 

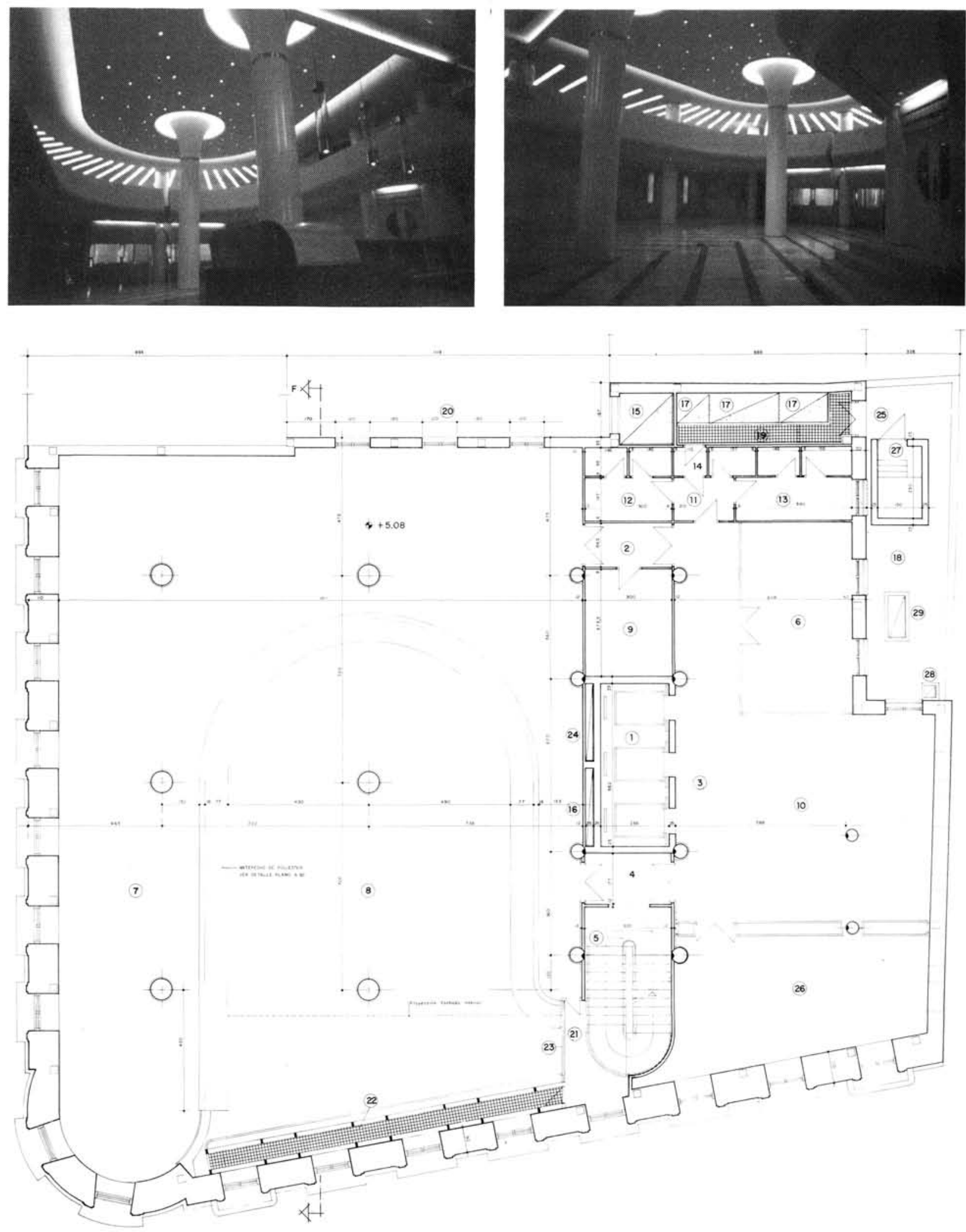

Planta 1:

1.-Ascensores. 2.-Acceso a oficinas. 3.-Vestibulo ascensores y escalera. 4.-Vestibulo independiente y acceso a oficinas. 5. - Escalera de planta baja a quinta. 6. Sala de firmas. 7. Oficina abierta. 8. Vacio sobre el patio de operaciones. 9. - Oficio de planta. 10. - Espera público. 11. -Vestibulo de aseos. 12. - Aseo de mujeres. 13. - Aseo de hombres. 14.-Acceso a conductos. 15. -Ventilación natural apar. camiento. 16. - Ventilación forzada aparcamiento. 17. - Conductos impulsión de aire acondicionado. 18. - Cubierta sobre planta baja. 19.Plenum de retorno y registro conductos. 20.-Patio de parcela. 21.-Acceso a pasarela limpieza fachada. 22.-Pasarela limpieza facha. da. 23. - Vidrio cortafuegos. 24. - Conductos eléctricos. 25. - Salida cubierta sobre planta baja. 26. - Despacho de técnicos. 27. - Cuarto maquinaria montacargas. 28.-Salida humos grupo electrógeno. 29.-Salida aire caliente grupo electrógeno. 


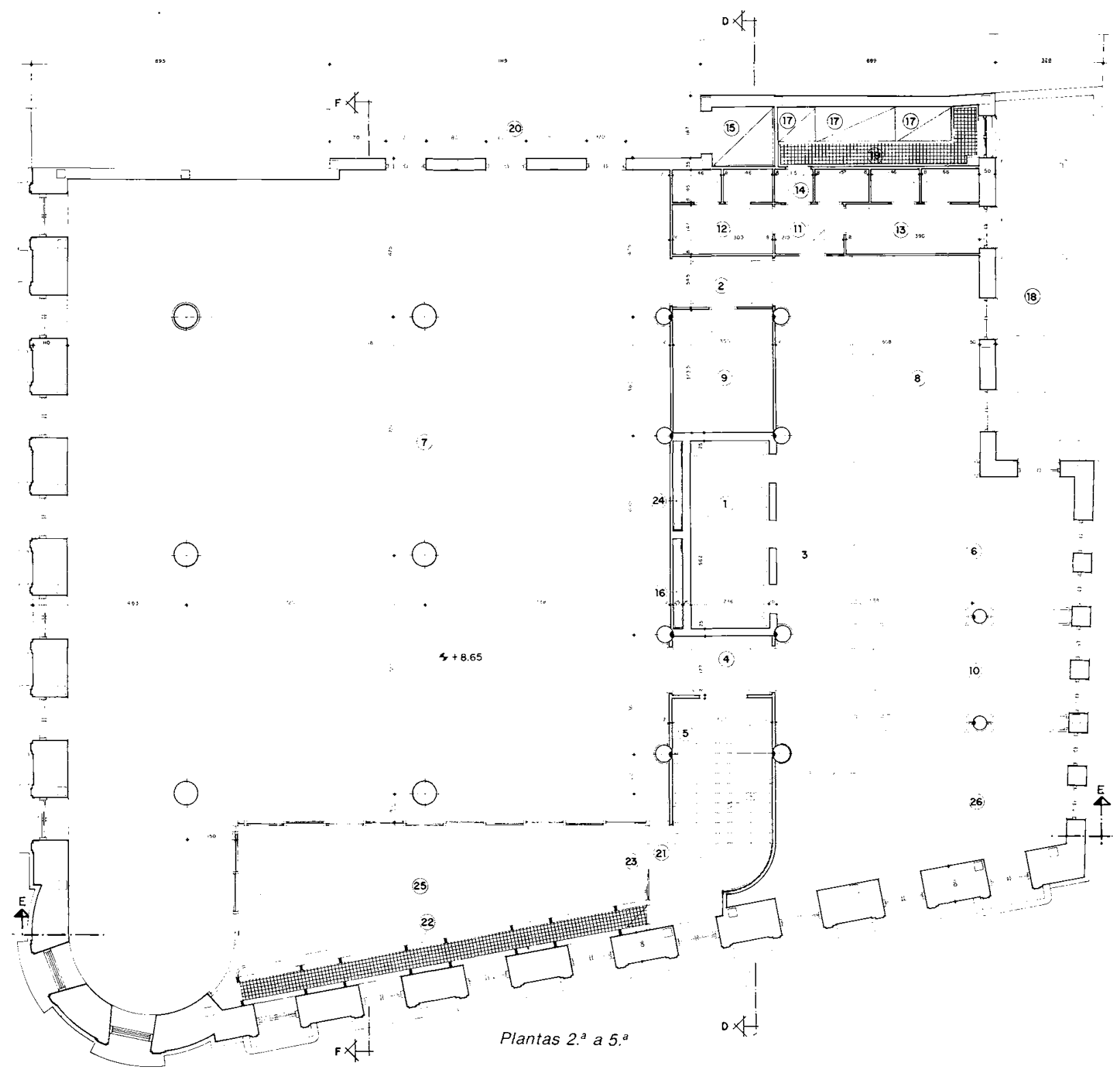

1.-Ascensores. 2.-Acceso a oficinas. 3.-Vestibulo ascensores y escalera. 4.-Vestibulo independencia y acceso a oficinas. 5.-Escalera de planta baja a quinta. 6.-Subdirector, Sucursal Madrid. 7.-Oficina abierta. 8.-Despacho de técnicos. 9.-Oficio de planta. 10.Secretarias. 11.-Vestibulo de aseos. 12.-Aseo de mujeres. 13.-Aseo de hombres. 14.-Acceso a conductos. 15.-Ventilación nafural aparcamiento. 16. - Ventilación forzada aparcamiento. 17. - Conductos impulsión aire acondicionado. 18.-Cubierta de planta baja. 19.Plenum de retorno y registro conductos. 20. - Patio de parcela. 21. - Acceso a pasarela. 22. - Pasarela limpieza fachada. 23. -Vidrio cortafuegos. 24.-Conductos eléctricos. 25.-Vacio sobre planta baja. 26.-Director, Sucursal Madrid.

\section{Proceso de construcción}

Antes de comenzar la demolición interior del edificio se realizó el correspondiente estudio geotécnico consistente en un reconocimiento de la naturaleza del terreno, de su estratigrafía, y en la determinación del nivel freático y de las propiedades del terreno, analizando los resultados para estudiar las tipologías más adecuadas de cimentación y los parámetros de cálculo.

Los resultados fueron positivos en cuanto a la naturaleza del terreno consistente en arenas de miga típica de Madrid y más profundamente arenas tosquizas y tosco de compacidad elevada.
Tan sólo resultó inquietante la aparición de niveles freáticos en algún punto a la cota $-8,00 \mathrm{~m}$.

Con respecto a los datos de cáiculo disponíamos de una resistencia de $3 \mathrm{kp} / \mathrm{cm}^{2}$.

El sistema de cimentación elegido fue el de zapatas aisladas en la zona central y muros pantalla perimetrales.

Previo a la demolición se realizó un gunitado interiormente en todas las fachadas de $10 \mathrm{~cm}$ de hormigón y 


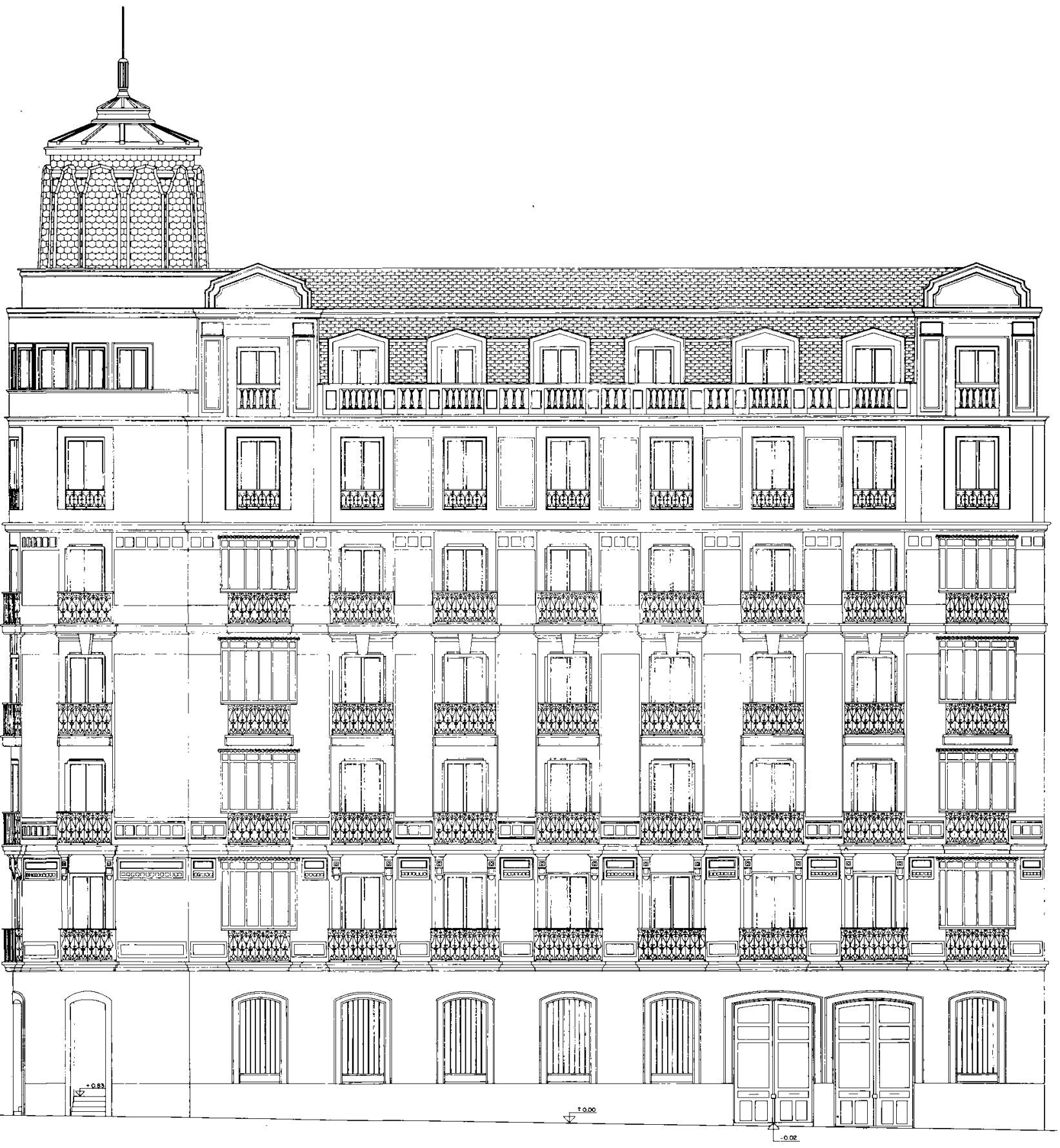

Alzado al $P^{\circ}$ de Recoletos.

mallazo, incluso en las medianerías. Posteriormente se instalaron los andamios estabilizadores de las fachadas. Hubo que utilizar hormigón para el contrapeso debido al poco espacio de aceras existente y para que a igualdad de peso con un cajón de grava, fuese menor su volumen. En definitiva, el contrapeso necesario ejercía una carga sobre el suelo de 16 toneladas por metro cuadrado.

Los andamios estabilizadores en las fachadas al Paseo de Recoletos y a la calle Recoletos fueron de tipo convencional; sin embargo no fue así con el andamio de la fachada sur o antigua medianería con el Palacio del Marqués de Salamanca, debido a la existencia de una edificación baja colindante. En este caso hubo que utilizar, mediante un ingenio estructural, la propia edificación citada como contrapeso.

Una vez instalados los andamios se realizó la demolición interior conservando el torreón de esquina apoyado en una viga triangulada realizada en tubo y de un canto equivalente a dos plantas del edificio que se apoyaba en una y otra fachada. 
Realizada la demolición se procedió a la ejecución de los muros pantalla. En las medianerias con otros edificios, en donde la máquina de excavación para las pantallas podia resultar ligeramente traumática, se adoptó la solución de pilotes muy próximos unos a otros y ejecutados por rotación.

Terminada la cimentación perimetral se procedió a la excavación. A medida que se excavaba se fue arriostrando el perimetro mediante antifuniculares metálicos, fundamentalmente para absorber el empuje originado por los contrapesos de fachada. La profundidad de tres sótanos obligó a la instalación de dos niveles de arriostramiento. Posteriormente se ejecutaron las zapatas y a medida que la estructura subia y se terminaban los forjados correspondientes a los sótanos se iban desmontando los antifuniculares.

Acabada la estructura se sustituyeron los andamios estabilizadores por andamios convencionales para proceder a la restauración de las fachadas.

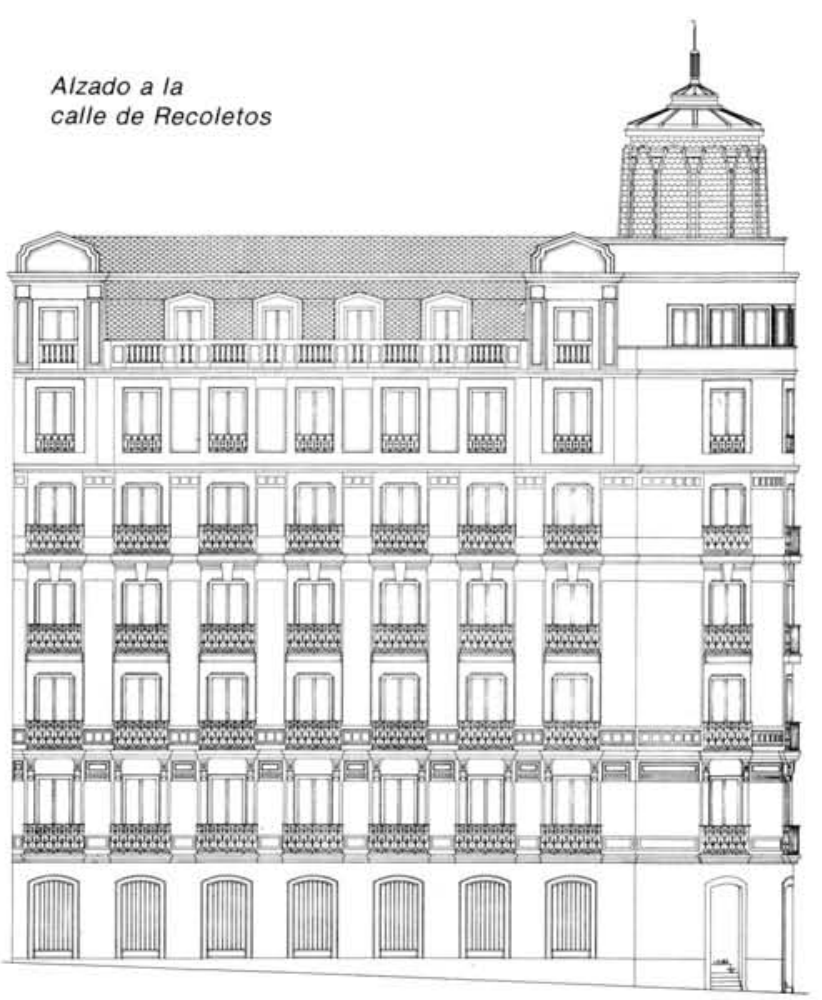

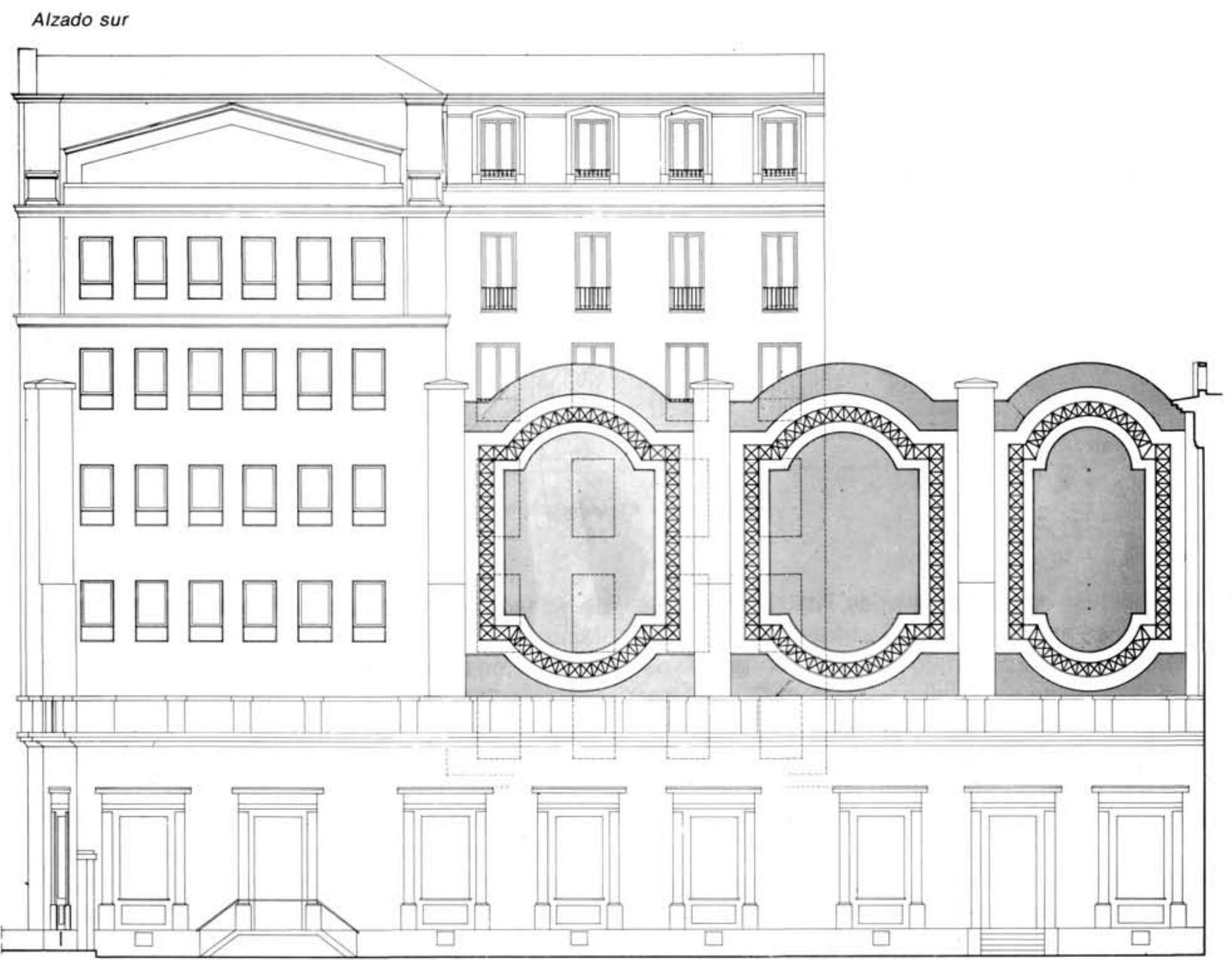




\section{Restauración de las fachadas}

Primeramente se hizo un picado general del viejo revoco (rasqueta de cal) y de los abolsados del enfoscado. Asimismo se picó la capa exterior de jambas, plafones y frisos. Las balaustradas tuvieron que ser demolidas por encontrarse en un estado irrecuperable, siendo reproducidas con exactitud formal.

Preparada la fachada para la restauración, las jambas y guarniciones asi como las impostas, plafones y frisos se tendieron y aterrajaron con material de yeso, escayola y adherentes naturales (no quimicos) recuperando los perfiles y textura originales, tratándolas finalmente con tres manos de pintura rebajada con objeto de que fuese convenientemente absorbida por el soporte. Los frentes y techos de repisas en balcones, cuya piedra de Novelda estaba en avanzado estado de descomposición por exfoliación, se sanearon restaurando las zonas picadas con mortero de cal, arena de mármol fino, cemento y aditivo natural, recuperando los pèrfiles $y$ volúmenes originales mediante aterrajados in situ.

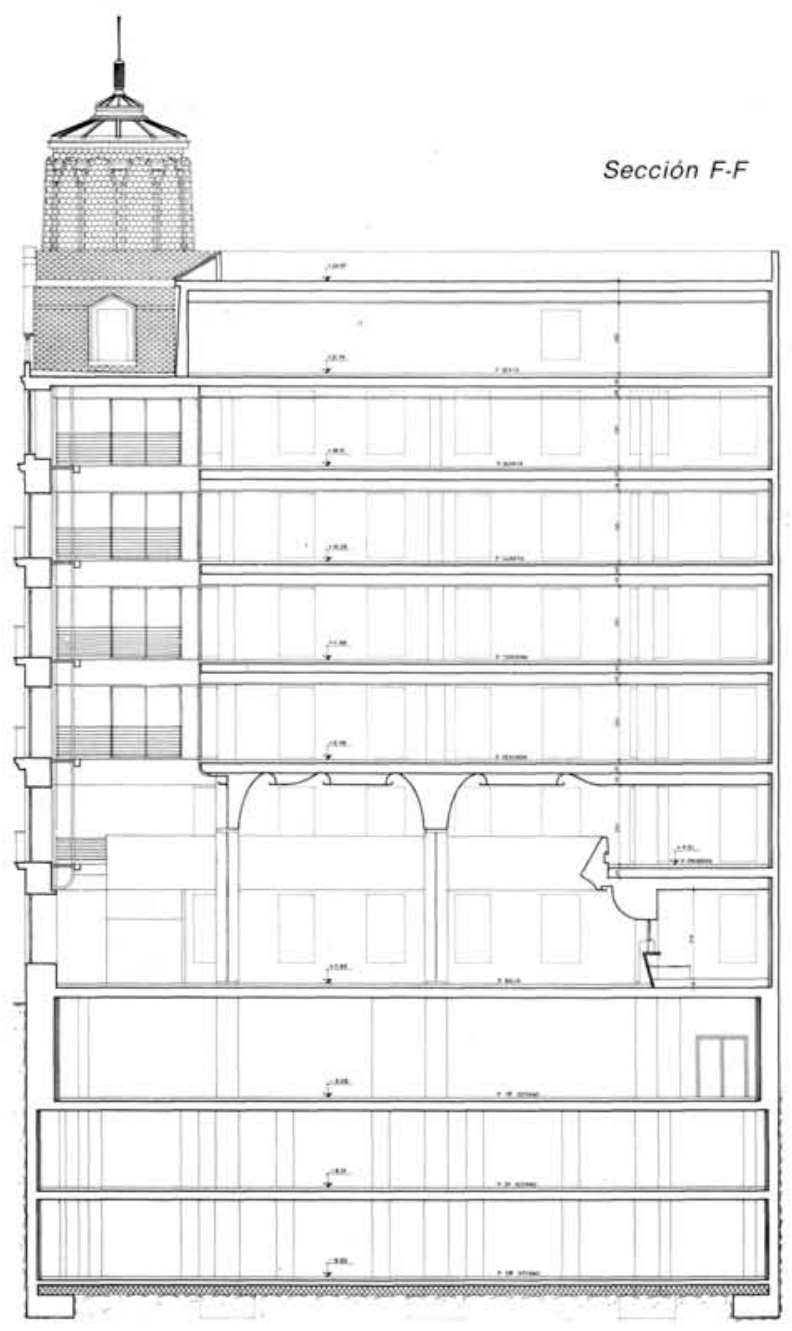

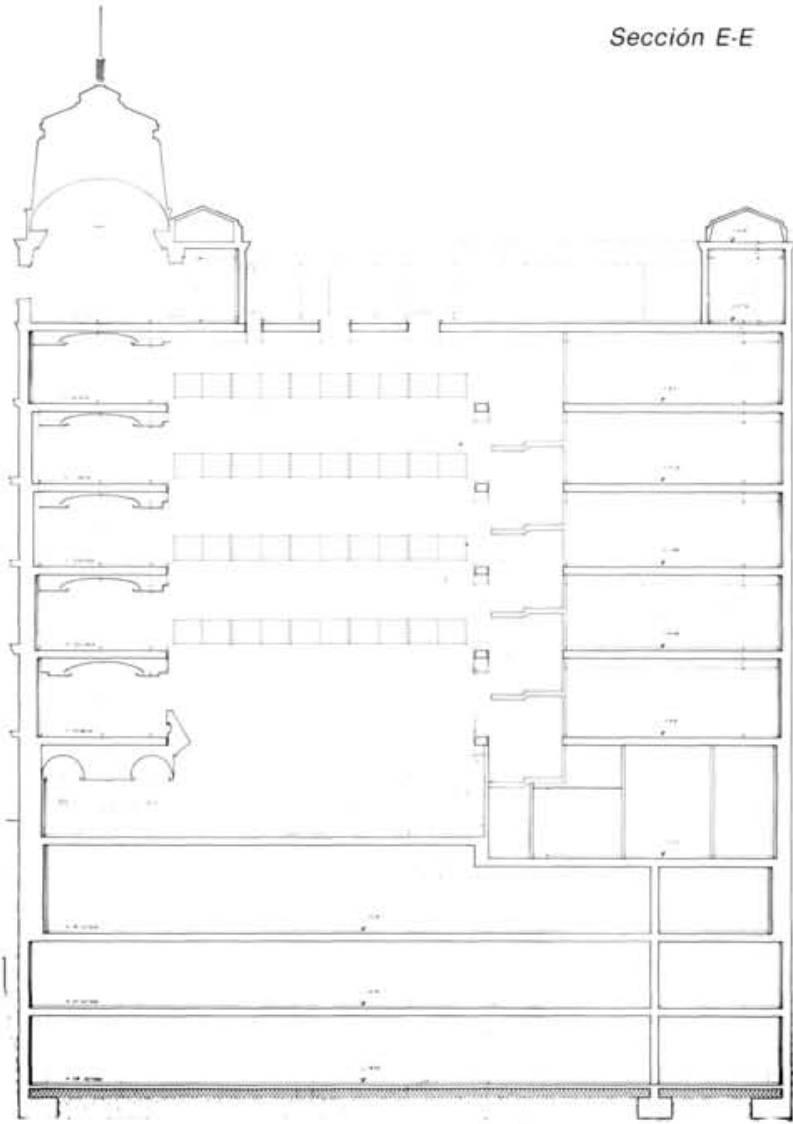

El revoco se ha realizado aplicando dos manos de material a base de cal grasa quemada con leña y envejecida naturalmente durante ocho meses, arena fina de mármol Macael y pigmentos minerales naturales. La ejecución ha sido de tendido con fratás y raspado con rasqueta fina.

En cuanto a la cerrajeria, en general se ha cepillado y pintado a la plombagina en color gris marengo.

Para elegir el color de fachada se hicieron todas las pruebas necesarias, buscando una entonación en gama con el color de la piedra de Novelda y que, al mismo tiempo, armonizase con el tratamiento del antiguo Palacio.

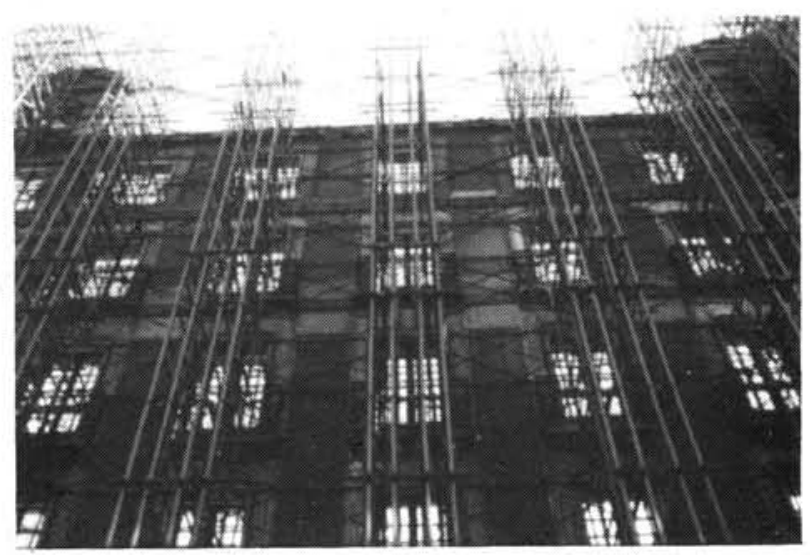



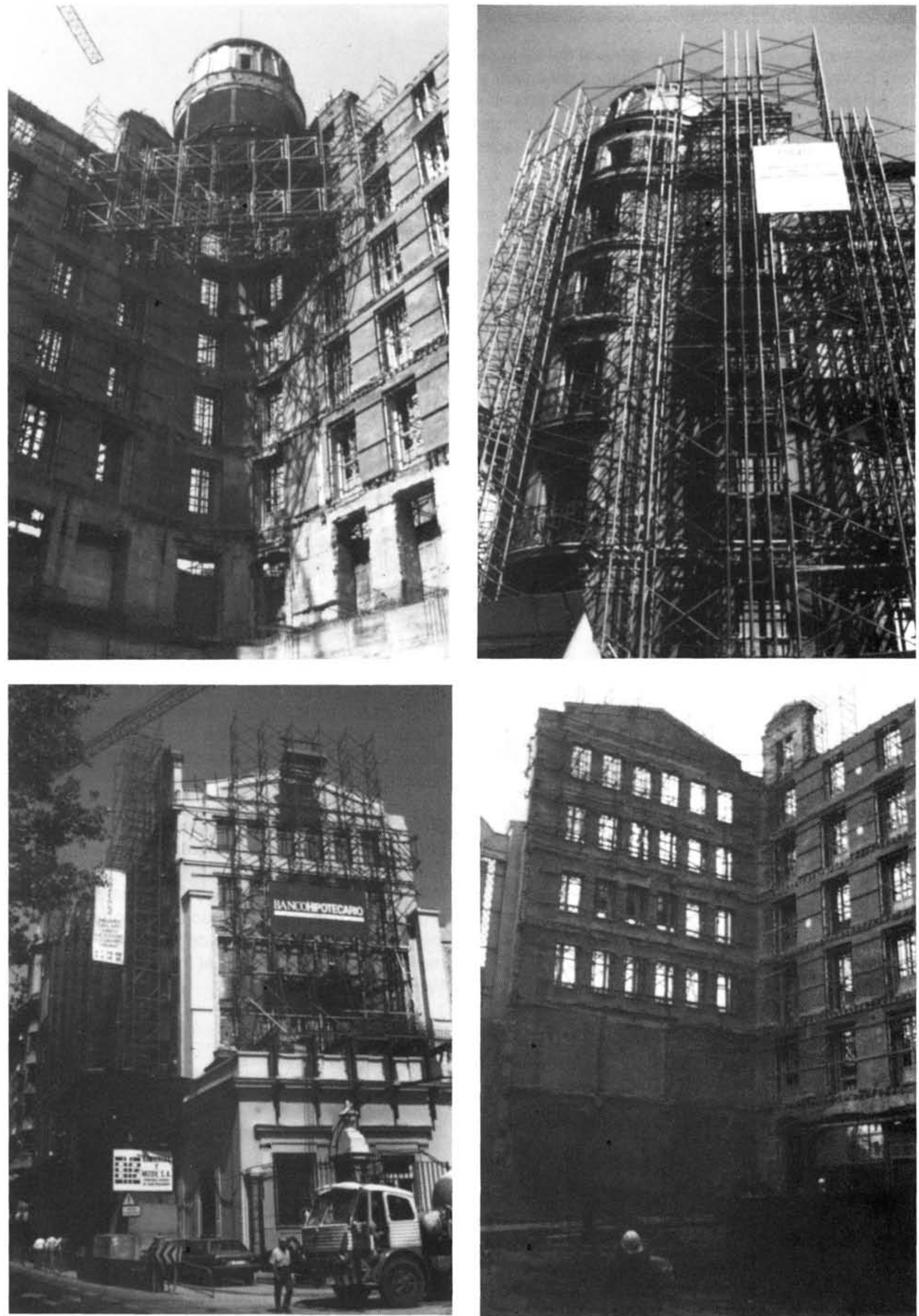


\section{Instalaciones}

El bloque eléctrico se desarrolla a la derecha del acceso de vehiculos y entre dicho acceso y la medianeria con el antiguo Banco. Consta de centro de transformación, a fachada, grupo electrógeno y cuadro eléc. trico general.

El edificio no dispone individualmente de equipo de continuidad, sino que se conecta la instalación al equipo ya existente en el edificio actual del Banco.

La instalación de climatización se resuelve mediante bombas de calor en cubierta y una doble instalación de temperatura variable y caudal constante en el perimetro del edificio, y de caudal variable y temperatura constante en el interior.

En la instalación de detección y extinción de incendios se ha tenido en cuenta escrupulosamente la normativa, tanto la Ordenanza del Ayuntamiento de Madrid como la NBE-CPI-82. Para mayor abundamiento existe un sistema de presurización del recinto de la escalera del edificio que se activa en caso de incendio.

\section{Un edificio automatizado}

El desarrollo de la microelectrónica ha facilitado el poder satisfacer ampliamente las necesidades de confort y seguridad que hoy debe tener un edificio administrativo.

Así, pues, la nueva sede del B. H. E. va equipada con un sistema automático de gestión y control.

Dicho sistema proporciona una gran reducción de cos tes por un mayor aprovechamiento energético y una mayor facilitad de atención y mantenimiento de las instalaciones.

El control automático se extiende a la climatización, iluminación artificial, instalaciones de detección y ex tinción de incendios, ventilación y planes de evacua ción del edificio.

Para el correcto funcionamiento del sistema cada una de las instalaciones dispone de controles de regulación con el fin de conseguir aquello que se espera de éllas.

Existen programas de ordenador dedicados al control de cada una de las instalaciones del edificio, al mis. mo tiempo que otros programas más generales las analizan en su conjunto y toman decisiones.

El sistema está abierto a la intervención del usuario complementando con nuevos programas los servicios requeridos en cada momento.

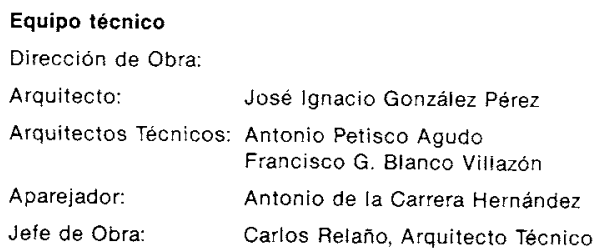

